\title{
NANOVECTORS FOR TRANSDERMAL ADMINISTRATION: WHERE ARE WE?
}

\author{
FRANCESCO CILURZO (*), SILVIA FRANZÉ, UMBERTO M. MUSAZZI
}

SUNTO. - La pelle è preposta a prevenire l'assorbimento di sostanze esogene. Questa funzione è esercitata dallo strato più superficiale dell'epidermide, lo strato corneo, costituito da circa 15-20 strati di corneociti parzialmente sovrapposti e supportati da un'impalcatura di cheratina. Gli spazi extracellulari sono riempiti con una matrice lipidica molto densa organizzata in lamelle periodiche. Gli spazi interlamellari sono invece costituiti da una matrice lipidica più fluida. Infine, dove i corneociti non sono perfettamente sovrapposti si creano dei pori a maggior contenuto di acqua. Questa complessa organizzazione permette la diffusione passiva solo di piccole molecole con peculiari proprietà chimico-fisiche. In tutti gli altri casi in cui sia auspicabile la veicolazione transdermica è necessario ricorrere all'impiego di tecniche che alterino in modo reversibile la funzionalità dello strato corneo come i promotori chimici dell'assorbimento, la ionoforesi o la sonoforesi. Nell'era delle nanotecnologie, un intenso sforzo è stato dedicato alla ricerca di nanovettori in grado di eludere le difese della pelle (nanoparticelle polimeriche, metalliche o solido-lipidiche, micro e nanoemulsioni, vescicole lipidiche). I risultati sono tuttora contrastanti e vi è nella comunità scientifica scetticismo sui reali vantaggi di questi sistemi rispetto agli altri approcci più tradizionali. Infatti, anche considerando lo strato corneo come una membrana nanoporosa con aperture di circa $20-40 \mathrm{~nm}$, le dimensioni della maggior parte dei nanovettori sono tali da non consentirne teoricamente la diffusione. Tuttavia, nonostante queste criticità sul mercato si trovano alcuni medicinali costituiti da vescicole lipidiche "ultradeformabili". Partendo dall'analisi critica delle informazioni reperibili sui possibili meccanismi di penetrazione delle diverse tipologie di nanovettori si cercherà di evidenziare luci ed ombre della somministrazione di questi sistemi sulla cute.

$* * *$

ABSTRACT. - The skin is the most important barrier of human body to prevent the absorption of exogenous substances. Its ability to limit the absorption of exogenous substances is exercised by the most superficial layer of the epidermis, the stratum corneum, which

(*) Dipartimento di Scienze Farmaceutiche, Università degli Studi di Milano, Italia.E-mail: francesco.cilurzo@unimi.it 
consists of about 15-20 layers of corneocytes supported by keratin fibres. The extracellular spaces are filled with a very dense lipid matrix organized in periodic lamellae, whereas the interlamellar spaces are constituted by a more fluid lipid matrix. In addition, where the corneocytes are not perfectly overlapped, pores with a higher water content are created. This complex organization allows only the passive diffusion of small molecules with peculiar chemical-physical properties. In all the other cases, it is necessary to improve the transdermal absorption of drugs using techniques able to alter reversibly the functionality of the stratum corneum, such as chemical skin penetration enhancers, iontophoresis or sonophoresis. In the era of nanotechnology, an intense effort has been made to design nanocarriers able to permeate the skin (e.g., polymeric nanoparticles, metal or solid-lipid, micro- and nanoemulsions, lipid vesicles). Nevertheless, the results are contradictory and there is scepticism in the scientific community about the real benefits of these systems compared to other traditional approaches. In fact, assuming the stratum corneum as a nanoporous membrane with openings of about 20-40 nm, the size of most of the nanocarriers is too big for permitting theoretically the skin penetration and diffusion. However, despite this consideration, on the market there are some medicinal products consisting of lipid vesicles. Starting from the critical analysis of the published information on possible permeation mechanisms of different types of nanocarriers, this review outlines lights and shadows on the (trans-)dermal administration of these drug delivery systems.

\section{INTRODUCTION}

The (trans)dermal administration of drugs may be advantageously exploited to overcome the limits related to the poor oral bioavailability of many compounds and to minimize the side effects associated to parenteral route. Moreover, it allows to reach both a local or a systemic effect. Nevertheless, the skin structure evolved to prevent the contact of the body with exogenous molecules thanks to the excellent barrier properties of the stratum corneum, which is the outermost layer of the skin having a highly packed structure. When observed in longitudinal section, the stratum corneum appears as a wall composed of several columns of partially overlapped corneocytes (Fig. 1). Each brick of this wall is made of 12-15 layers of corneocytes surrounded by a crystalline lipid matrix, organized in periodic lamellae. However, some defects in these junctions exist and, as a result of the imperfect overlapping of cell membranes, the whole structure could be considered as a poorly permeable nano-porous membrane (Cevc and Vierl, 2010) with a water content of about $10 \%$ (Fig. 2). Considering the overall complexity of the skin, only few compounds having peculiar features can passively diffuse through this barrier. In general, such molecules have a low molecular weight $(<500 \mathrm{Da})$, they do not have charge and they have a good hydrophilici- 
ty/lipophilicity ratio $(\log P \sim 2-3)$. The passive diffusion of other compounds has to be enhanced by specialized techniques. Such approaches are based on the perturbation of the architecture of the stratum corneum that can be achieved by chemical or physical enhancement techniques (William and Barry, 2004; Swain et al., 2011). The use of chemical skin penetration enhancers represents the long-standing approach for improving transdermal delivery of drugs. They are small molecules able to penetrate in the intercellular regions of the stratum corneum and increase the fluidity of the lipid components determining a temporary disruption of the skin barrier properties (William and Barry, 2004). Alternatively, they may increase the drug solubility in the stratum corneum and, improving the drug thermodynamic activity, favour the passive diffusion process through the skin. Among the physical enhancement techniques, the iontophoresis and electroporation are the widely studied since the perturbation of the stratum corneum is reversible conversely to sonophoresis and the use of microneedles, which determine a disruption of its structure (Swain et al., 2011).

Besides these well-established approaches, the possible use of nanovectors is also studied as demonstrated by the number of articles published in the last two decades which increased in an exponential fashion.
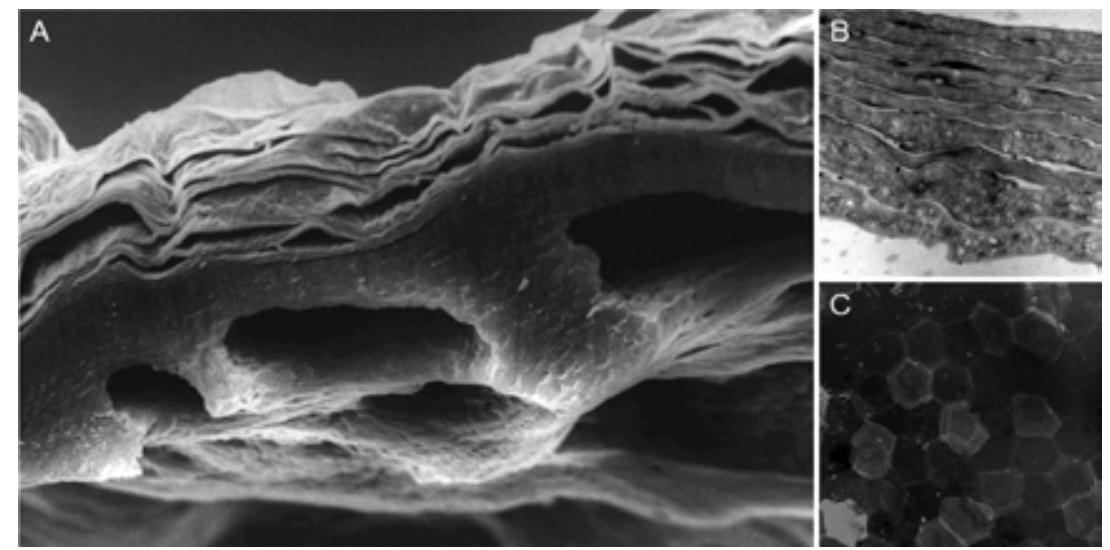

Fig. 1. Structure of human epidermis: A) cross-sectional view of human epidermis showing stratum corneum desquamation (SEM image); B) lamellar structure of buman stratum corneum (TEM image); C) planar view of stratum corneum showing the hexagonal shape of corneocytes (confocal microscope image). 


\section{NANOVECTORS AS (TRANS)DERMAL DELIVERY SYSTEMS}

The nanovectors have been widely investigated to target a specific organ after parenteral administration and in this case the main issues in their clinical development are related to the uptake into the cells of the mononuclear phagocyte system and the difficulty to selectively target the pathological tissue. In the case of the cutaneous administration, these issues are further complicated by the stratum corneum properties that significantly limit the bioavailability of nanovectors (Fig. 2). Thus, the use of nanotechnology should be thought mainly to target a drug in the deep layers of viable epidermis and/or dermis, rather than to obtain a systemic or regional pharmacological effect. Altogether, the nanosystems proposed for a cutaneous administration have been studied to reach one or more goals:

- to favour the partition of a drug into the stratum corneum or viable epidermis;

- to prevent the systemic absorption of the drug through the capillaries in the dermis;

- to perform an occlusive function increasing the hydration of corneocytes and widening the hydrophilic pores (channel-like hydrophilic pathway, Fig. 2) within the lipids of stratum corneum;

- to act as a local depot of the drug in the outer skin layers to delay the frequency of administration (this is desirable for drugs such as antibiotics, corticosteroids).

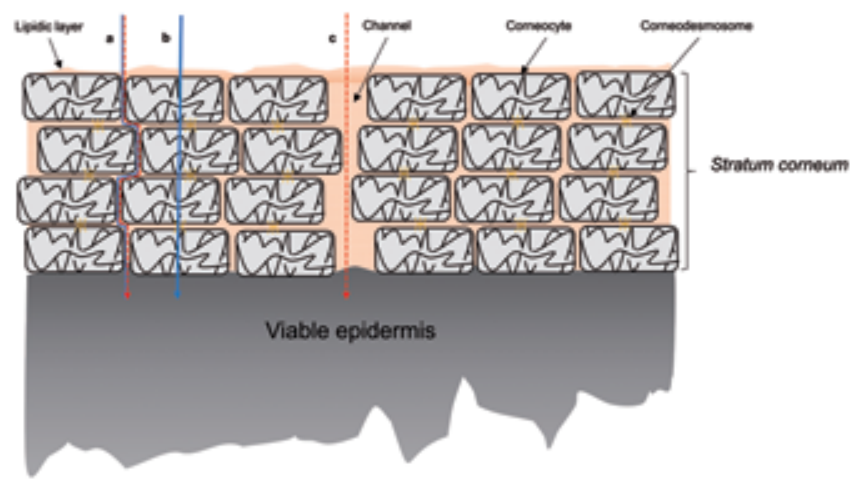

Fig. 2. Scheme of the stratum corneum organization, showing the potential corneocyte alignment and the channels formed by the imperfect overlapping of their membranes; preferential permeation pathways of drugs (solid blue lines) and nanovectors (dashed red lines) through stratum corneum: a) intercellular, b) transcellular, c) channel-like hydrophilic pathway. 
Moreover, they could behave as skin penetration enhancers and, more in general, as controlled drug delivery systems.

The characteristics of the most frequently studied nanovectors are described in the following sections and their performances discussed on the basis of the considerations reported above.

\subsection{Nanovesicles}

The use of lipid to design nanovesicles is undoubtedly the most investigated approach over the past twenty years. The first efforts dealt with liposomes, which are made of lipid bilayers enclosing aqueous compartments (Fig. 3). However, conventional liposomes are unable to penetrate the stratum corneum due to their stiffness. Nowadays, it is generally recognized that they can only enhance the drug retention into the skin disintegrating or fusing on the skin surface, thus exchanging lipid components with the stratum corneum and favouring the drug release (Cosco et al., 2008). Hence, they can be advantageously used only to treat superficial skin diseases when a local depot is required.

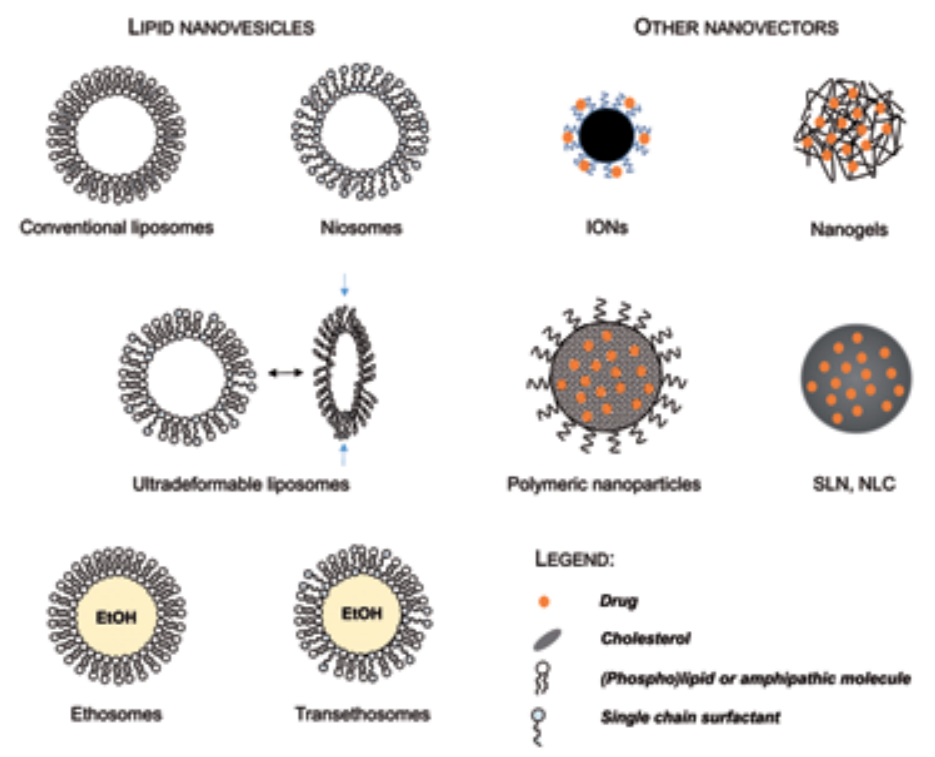

Fig. 3. Main types of nanovectors that have been investigated as (trans) dermal drug delivery systems. Blue arrows indicate the relocation of the single chain surfactant in the areas of maximum pressure during the deformation of ultradeformable liposomes. 
Thus, many formulative modifications of the basic composition of liposomes have been made to ameliorate their efficiency after application onto the skin.

Niosomes are self-assembled vesicles composed of non-ionic surfactants having a suitable packing parameter to form bilayers stabilized by cholesterol which lends, as in the case of phospholipids, to ordered structures and a modulation of the membrane's permeability (Khan et al., 2016, Fig. 3). Since niosomes are characterized by a higher chemical stability with respect to liposomes, they have been proposed for a great variety of applications in the field of drug delivery, including their use for the cutaneous delivery of several active molecules (Abidin et al., 2016; Auda et al., 2016; Ghanbarzadeh et al., 2015; Gupta et al., 2016; Ioele et al., 2015; Lather et al., 2016; Moghddam et al., 2016; Pando et al., 2015; Zidan et al., 2016).

The penetration mechanism in the case of niosomes is comparable to that described in case of conventional liposomes. First, they improve the thermodynamic activity of drugs acting as solubilizing agents; moreover, similarly to lipid vesicles, they partially loosen the lipid barrier of the stratum corneum fusing or aggregating on the skin surface (Ogiso et al., 1996), thus behaving as skin penetration enhancers.

However, besides the existence of some scientific evidences on the efficacy of such systems (Manca et al., 2016), huge doubts remain about their real penetration pattern after the cutaneous application and the real usefulness of these systems in cutaneous drug delivery.

Conversely, a further modification of the bilayer composition of liposomes led to the development of proper novel generations of lipid vesicles defined as "ultradeformable liposomes" and "ethosomes". The "ultradeformable" liposomes were described for the first time in 1992 by Cevc and co-workers and patented with the name of Transferosomes (IDEA AG) (Cevc et al., 1992). In their basic structure, these systems are composed of phospholipids having fluid chains, and a single chain, nonionic surfactant, which destabilizes the bilayer allowing shape deformation at low energetic cost which permits the vesicles to pass through pores having a diameter up to one tenth of their radius (Romero et al., 2013, Fig. 3). The force that drives the penetration of these vesicles seems to be the osmotic gradient. However, this potential mechanism of action is questioned since the water gradient would be abolished at the stratum corneum/epidermis interface and the hydrophilic pores are rare furrows. However, after dermal application of radioactive labelled transferosomes 
on a model animal, Cevc and Blume found moderate radioactivity levels in blood, whereas it was revealed in the liver suggesting the penetration of transferosomes as intact vesicles, since the organ cannot accumulate simple lipid molecules (Cevc and Blume, 1992). The hypothesis of entire vesicles penetration is also supported by the efficiency of these carriers in enabling the skin delivery of macromolecules such as insulin (Cevc et al., 1996), other large proteins for immunization (Paul A. et al., 1995), low molecular weight heparins (Song et al., 2006; Song et al., 2011), siRNA (Geunsens et al., 2009).

As a consequence of these promising data, a number of carriers are currently under clinical investigation for the treatment of several local pathologies. For a complete review see Romero and Morilla (2013) and Morilla and Romero (2016).

Ethosomes are highly fluid vesicles derived from the combination of phospholipids and high ethanol content (20-45\%), proposed for the first time by Touitou and co-workers in 2000 (Touitou et al., 2000, Fig. 3). The presence of the alcoholic counterpart notably increases the permeability of the bilayer, which is less packed, and lends to the particles a negative zeta potential responsible of an increased colloidal stability (Morilla and Romero, 2016). Since ethanol is also a well-known skin penetration enhancer, the increased penetration of such carriers through the skin barrier would be the result of a synergistic action of ethanol and lipid vesicles. In particular, ethanol is able to intercalate into the polar heads of the lipids of the stratum corneum loosening their tight organization and creating some gaps that would open the passage to the vesicles, which are fluids for the presence of ethanol itself (Touitou et al., 2000). Following this pathway, ethosomes would enable the flux of the carried active molecules deeply into the skin, up to the dermis, where they can be absorbed to reach systemic effect. Then, compared to deformable liposomes, they are not the most suitable carriers when a local effect is desirable (Campani et al., 2016).

Moreover, with respect to deformable liposomes, ethosomes can be applied under occlusive conditions and they can be formulated also as a transdermal patch (Romero et al., 2014), which is the most accepted transdermal dosage form. Touitou and co-authors (2000) compared the performances of patches containing ethosomal testosterone with those of the commercial patch Testoderm ${ }^{\circledR}$. They found a 30-time increase of the in vitro permeated amount of testosterone through rabbit skin when it was delivered by ethosomal system in comparison to conventional patch. 
The ethosomal patch also confirmed its higher efficacy in vivo, leading to higher blood level of testosterone after 5 days of application. Recently, glimepiride transdermal films loaded with a drug in ethosomal formulation were proposed as a valuable alternative to conventional oral tablets, since they showed a prolonged drug release with an in vitro good permeation profile of the active molecules. Moreover, the pharmacokinetic studies on human volunteers evidenced a decrease of the $\mathrm{C}_{\max }$ with respect to tablets, with following diminution of the side effects often associated to the oral administration of glimeripide (Ahmed et al., 2016).

A further improvement of ethosomes performances was obtained with the development of transethosomes, that, as suggested by their name, combine the deformability properties of transferosomes with the high fluidity of ethosomes, having in their composition both ethanol and an edge activator (e.g., a surfactant or a skin penetration enhancer) (Fig. 3) (Song et al., 2012). However, also in this case, many efforts are required to better comprehend the real pathway of penetration of these vesicles and their efficacy on human skin in vivo.

\subsection{Solid lipid nanoparticles}

The solid lipid nanoparticles (SLN) and nanostructured lipid carriers (NLC) are spherical-like nanostructures characterized by a homogeneous inner structure of lipids that are solid at room temperature (Pardeike et al., 2009; Fig. 3). With respect to SLN which are composed only by a solid matrix, the lipidic phase of NLC can also contain lipids with lower melting points. SLN and NLC can be conveniently prepared using techniques (e.g., high pressure homogenization) that allow a fast production and an easy scale up, avoiding the use of organic solvents. In addition, small molecules, peptides and proteins can be homogenously dispersed in the SLN matrix (Almeida and Souto, 2007). Considering these advantages, SLN were extensively studied as nanovectors for both pharmaceutical and cosmetic applications. In particular, SLN were proposed in cosmetic products for protecting active ingredients and increasing their penetration through the upper layers of human skin (Müller et al., 2002). Indeed, Detoni and co-authors (2012) compared the performances of NLC loaded by resveratrol to those of liposomes and lipid-core nanocapsules in terms of chemical stability of the loaded drug and in vitro penetration profile through porcine skin. The results demonstrated that after exposure of UV-A radiation, NLC 
were more stable than liposomes protecting resveratrol from isomerization in the same extent that lipid-core nanocapsules. In addition, the permeation profile of resveratrol loaded in NLC was superimposable to that of the free-drug, when experiments were conducted in dark conditions; on the contrary an important improvement in the drug permeated amount was obtained when the dermis was exposed to UV-A radiation. However, these encouraging results of SLN or NLC were not due to the ability of the nanovector itself to penetrate through the skin. Since lipids used to design SLN or NLC generally melt at the skin temperature (i.e., $32^{\circ} \mathrm{C}$ ), after cutaneous application both SLN and NCL melt on the skin surface, forming an adhesive layer with occlusive properties (Schäfer-Korting et al., 2007). The consequent increase of the stratum corneum hydration, is the key factor to enhance the skin penetration of a drug (Wissing et al., 2001).

\subsection{Polymer-based nanovectors}

\subsubsection{Polymeric nanoparticles}

Polymeric nanoparticles are nanostructures formed by a dense polymeric matrix, which ranges from $20 \mathrm{~nm}$ to about $500 \mathrm{~nm}$ (Fig. 3). Their possible application to transdermal delivery was systematically studied by Alvarez-Román and co-authors (2004), using fluorescent polystyrene nanoparticles as model nanovector. The results evidenced that both $20-\mathrm{nm}$ and $200-\mathrm{nm}$ nanoparticles were not able to permeate significantly through the porcine skin, but $20-\mathrm{nm}$ nanoparticles were highly distributed in follicular space. In agreement with these results, Vogt et al. demonstrated that only 40-nm polystyrene nanoparticles could distribute in hair follicles and permeated via their epithelium to distribute in the epidermal layer (Vogt et al., 2006). Other authors suggested that polymeric nanoparticles could penetrate skin via follicular route when its barrier properties were altered. As an example, AbdelMottaleb et al. showed that ethyl cellulose nanoparticles (diameter $<500 \mathrm{~nm}$ ) significantly permeated through a mice skin model of dithranol-induced dermatitis inflammation (Abdel-Mottaleb et al., 2012a). Again, Try et al. showed that the skin penetration of 70-nm PLGAnanoparticles was significantly increased both in murine and pig models of atopic dermatitis (Try et al., 2016). In particular, the accumulation of nanoparticles were 15 -fold and 3 -fold higher in murine and pig 
inflamed skin, respectively, in comparison to corresponding healthy membranes.

\subsubsection{Nanogels}

Nanogels are a particular type of polymeric nanoparticles characterized by a loose inner structure, so that they can be imagined as nanosponges (Mavuso et al., 2015; Fig. 3). Made of synthetic (e.g., PLGA, Eudragit ${ }^{\circledR}$ RL 100) or natural polymers (e.g., chitosan, chitin, hyaluronic acid, gellan), they are obtained by chemically or physically crosslinking of polymeric chains in spherical-like networks (Di Meo et al., 2015). This peculiar structure, along with the related physicochemical properties, permits designing nanogels with a high drug loading and able to be stimuli responsive (Chacko et al., 2012), increasing the interest for their possible clinical applications.

In the field of transdermal drug delivery, they were recently proposed for the administration of both small molecules and proteins. Divya et al. prepared chitin nanogels loaded by two anti-psoriasis drugs, namely acitretin and aloe-emodin (Divya et al., 2016). Although the dimension of these nanogels ranged from 100 to $250 \mathrm{~nm}$, the in vitro permeation studies through pig ear skin showed that the retention and permeation profiles of drug-loaded nanogels were similar or higher than the control, a drug methanolic solution. Samah and Heard (2013) demonstrated that stimuli responsive nanogels, made of poly $(\mathrm{N}$-isopropylacrylamide) and acrylic acid, were also able to improve the permeation profiles of small molecules (i.e., caffeine). Finally, Choi et al. (2012) demonstrated that Pluronic/chitosan nanogels were able to penetrate through the stratum corneum of human cadaver skin, improving the permeation profile of FITC-BSA.

As in the case of the previous nanovectors, the permeation mechanism of nanogel through animal and human skin models is far from being completely clarified. On the basis of the results obtained by polyglycerol-based nanogels, Rancan et al. (2016) suggested that their effectiveness to enhance the drug permeation could be related to their softness and their high stability due to the crosslinking. On the contrary, Smejkalova et al. (2017) showed that hyaluronan polymeric micelles, which have a nanogel-like structure, were able to permeate through pig ear skin, but they lost their structure in the deepest layers of the skin. 


\subsection{Metallic nanocarriers}

Several inorganic nanosystems of various shape and materials, such as metals (e.g., gold, silver), metal oxide (e.g., iron oxide, zinc oxide, titanium dioxide), carbon or silica, were widely studied for dermatologic applications (Papakostas et al., 2011; Fig. 3). Nevertheless, only nanomaterials made of zinc or titanium oxides are currently used in cosmetic products as physical sunscreen filters. Recently, the interest of scientific community for inorganic core nanoparticles (IONs) intended as drug-loaded nanovectors for treating cutaneous diseases has risen (Lee et al., 2015; Santini et al., 2015). Constituted by an inorganic core, made of iron oxide or gold, coated by a polymer, such nanovectors combine the advantages given by the peculiar physicochemical properties of the inorganic core with the possibility to deliver active pharmacological moieties (e.g., small molecules, peptides, nucleic acids; Lee et al., 2015; Zheng et al., 2012). In particular, ironoxide nanoparticles, which can be detect by MRI due to their superparamagnetic properties (Rockall et al., 2005), could be proposed as theranostic agent for cutaneous or loco-regional diseases. According to literature, the skin permeation of inorganic nanovectors was significantly influenced by the core size, core shape and type of polymeric coating. Sonavane et al. (2008) demonstrated that both the permeation and the diffusion of gold nanoparticles through rat skin decreased significantly when the particle diameter moved from 15 to $105 \mathrm{~nm}$.

The selection of a proper coating for IONs resulted also critical because of its impact on both the core stability in aqueous vehicle (Santini et al., 2015) and nanoparticles skin penetration (Baroli et al., 2007; Hsiao et al., 2016). As an example, the permeation profile of gold nanoparticles (diameter measured by DLS: $20-40 \mathrm{~nm}$ ) was significantly improved if they were coated by poly-(ethylene glycol) (Hsiao et al. 2016). Similarly, the surface coating of IONs (diameter measured by TEM: $<20 \mathrm{~nm})$ can alter their penetration profiles through full-thickness skin (Baroli et al. 2007). Nevertheless, the capability of IONs to permeate the skin is far from being univocally proved. Indeed, although several studies have demonstrated the in vitro and in vivo permeation of such nanovectors in animal models, the scientific community is still discussing if such findings can be predictive of the IONs tendency to permeate the human skin (Monteiro-Riviere and Riviere, 2009). 


\section{CONCLUSIONS}

Despite the possible advantages of nanovectors to improve the therapeutic performances of some active ingredients, the mechanism of penetration is not completely understood since contradictory results are available in literature. One of the reasons can be due to the species used in the skin penetration experiments and, in some cases, the experimental conditions. These differences are underlined by comparing the results obtained after exposing the skin of different mammalians to quantum dots (QD) that are nanoparticles in the $14-45 \mathrm{~nm}$ range characterized by an intense and photostable fluorescence (Monteiro-Riviere and Riviere, 2009). Indeed, QD were found in the liver of hairless mouse after their application on the intact skin suggesting that these nanoparticles could be minimally absorbed after transdermal administration (Tang et al., 2013; Gopee et al., 2009). In the case of rats, QD are able to reach dermis only depending on their morphology and surface characteristics (Zhang and Monteiro-Riviere, 2008; MonteiroRiviere and Riviere, 2009) and to penetrate in the porcine epidermis (Ryman-Rasmussen et al. 2006) and reach the stratum granulosum as in the case of fullerenes (Rouse, et al., 2007), but remained confined on the stratum corneum surface when applied on the human skin (Gratieri et al., 2010). Therefore, further investigations are required to better understand the possible mechanistic aspects involved in the penetration of these nanovectors rather than to obtain proofs of concept of their efficiency in different animal models, whether the human skin cannot be used as skin model in in vitro permeation studies.

In conclusion, although the great number of attempts made on this field, up to now we are still far from the development of cutaneous dosage forms containing nanovectors able to deeply penetrate the skin barrier for treating effectively severe diseases. Indeed, the only drug products appeared on the European market are based on lipid vesicles, namely a conventional liposome intended for the localization in the stratum corneum of econazole, an antimycotic drug, and a transethosome designed to enhance the skin penetration of diclofenac. 


\section{REFERENCES}

Abdel-Mottaleb MMA, Moulari B, Beduneau A, Pellequer Y, Lamprecht A. Nanoparticles enhance therapeutic outcome in inflamed skin therapy. Eur J Pharm Biopharm 2012a;82: 151-157.

Abdel-Mottaleb MMA, Moulari B, Beduneau A, Pellequer Y, Lamprecht A. SurfaceCharge-Dependent Nanoparticles Accumulation in Inflamed Skin. J. Pharm Sci 2012b; 101:4231-4239.

Abidin L, Mujeeb M, Imam SS, Aqil M, Khurana D. Enhanced transdermal delivery of luteolin via non-ionic surfactant-based vesicle: Quality evaluation and anti-arthritic assessment. Drug delivery 2016;23(3):1079-1084.

Ahmed TA, El-Saya KM, Aljaeida BM, Fahmya UA, Abd-Allahb FI. Transdermal glimepiride delivery system based on optimized ethosomal nano-vesicles: Preparation, characterization, in vitro, ex vivo and clinical evaluation. Int J Pharm 2016; 500:245-254.

Almeida AJ, Souto E. Solid lipid nanoparticles as a drug delivery system for peptides and proteins. Adv Drug Del Rev 2007;59: 478-490.

Alvarez-Román R, Naik A, Kalia YN, Guy RH, Fessi H. Skin penetration and distribution of polymeric nanoparticles. J Contr Rel 2004;99:53-62.

Ascenso A, Raposo S, Batista C, Cardoso P, Mendes T, Praça FG et al. Development, characterization, and skin delivery studies of related ultradeformable vesicles. transfersomes, ethosomes, and transethosomes. Int J Nanomedicine 2015;10: 5837-5851.

Auda SH, Fathalla D, Fetih G, El-Badry M, Shakeel F. Niosomes as transdermal drug delivery system for celecoxib: in vitro and in vivo studies. Polymer Bulletin 2016;73:1229-1245.

Baroli B, Ennas MG, Loffredo F, Isola M, Pinna R, Lopez-Quintela MA. Penetration of Metallic Nanoparticles in Human Full-Thickness Skin. J Invest Dermatol 2007; 127:1701-1712.

Barry BW. Novel mechanisms and devices to enable successful transdermal drug delivery. Eur J Pharm Sci 2001;14:101-114.

Campani V, Biondi M, Mayol L, Cilurzo F, Franzé S, Pitaro M, De Rosa G. Nanocarriers to Enhance the Accumulation of Vitamin K1 into the Skin. Pharma Res 2016;33 (4):893-908.

Cevc G, Blume G. Lipid vesicles penetrate into intact skin owing to the transdermal osmotic gradients and bydration force. Biochim Biophys Acta 1992;1104(1):226-32.

Cevc G, Gebauer D, Stieber J, Schätzlein A, Blume G. Ultraflexible vesicles, Transfersomes, have an extremely low pore penetration resistance and transport therapeutic amounts of insulin across the intact mammalian skin. Biochimica et Biophysica Acta 1998;1368:201-215.

Cevc G, Vierl U. Nanotechnology and the transdermal route. A state of the art review and critical appraisal. J Contr Rel 2010;141:277-299.

Cevc G. Lipid vesicles and other colloids as drug carriers on the skin. Adv Drug Del Rev 2004;56:675-711. 
Cevc G. Rational design of new product candidates: The next generation of highly deformable bilayer vesicles for noninvasive, targeted therapy. J Contr Rel 2012; 160:135-146.

Chacko RT, Ventura J, Zhuang J, Thayumanavan S. Polymer nanogels: A versatile nanoscopic drug delivery platform. Adv Drug Del Rev 2012;64:836-851.

Choi WI, Lee JH, Kim J-Y, Kim J-C, Kim YH, Tae G. Efficient skin permeation of soluble proteins via flexible and functional nano-carrier. J Contr Rel 2012;157:272-278.

Cosco D, Celia C, Cilurzo F, Trapasso E, Paolino D. Colloidal carriers for the enhanced delivery through the skin. Expert Opin Drug Deliv 2008;5:737-755.

Danhier F, Ansorena E, Silva JM, Coco R, Le Breton A, Préat V. PLGA-based nanoparticles: An overview of biomedical applications. J Contr Rel 2012;161:505-522.

Detoni CB, Souto GD, da Silva ALM, Pohlmann AR, Guterres SS. Photostability and Skin Penetration of Different E-Resveratrol-Loaded Supramolecular Structures. Photochem Photobiol 2012;88:913-921.

Di Meo C, Montanari E, Manzi L, Villani C, Coviello T, Matricardi P. Highly versatile nanobydrogel platform based on riboflavin-polysaccharide derivatives useful in the development of intrinsically fluorescent and cytocompatible drug carriers. Carbohydr Polym 2015;115:502-509.

Divya G, Panonnummal R, Gupta S, Jayakumar R, Sabitha M. Acitretin and aloeemodin loaded chitin nanogel for the treatment of psoriasis. Eur J Pharm Biopharm 2016;107:97-109.

El Maghraby GM, Barry BW, Williams AC. Liposomes and skin: From drug delivery to model membranes; European journal of pharmaceutical sciences 2008;34:203-222.

El-Say KM, Abd-Allah FI, Lila AE, Hassan AE-SA, Kassem AEA. Diacerein niosomal gel for topical delivery: Development, in vitro and in vivo assessment. J Liposome Res 2016;26:57-68.

Elsayed MMA, Abdallah OY, Naggar VF, Khalafallah NM. Lipid vesicles for skin delivery of drugs: Reviewing three decades of research. Int J Pharm 2007;332:1-16.

Geusens B, Lamber J, De Smedt SC, Buyens K, Sanders NN, Van Gele M. Ultradeformable cationic liposomes for delivery of small interfering RNA (siRNA) into buman primary melanocytes. J Cont Rel 2009;133(3):214-220.

Ghanbarzadeh S, Khorrami A, Arami S. Nonionic surfactant-based vesicular system for transdermal drug delivery. Drug Deliv 2015;22(8):1071-1077.

Gopee NV, Robert DW, Webb P, Cozart CR, Siitonen PH, Latendresse JR, et al. Quantitative Determination of Skin Penetration of PEG-Coated CdSe Quantum Dots in Dermabraded but not Intact SKH-1 Hairless Mouse Skin. Toxicol Sci 2009;111:37-48.

Grams YY, Bouwstra JA. Penetration and distribution of three lipopbilic probes in vitro in buman skin focusing on the hair follicle. J Contr Rel 2002;83:253-262.

Gratieri T, Schaefer UF, Jing L, Gao M, Kostka K-H, Lopez RFV et al. Penetration of quantum dot particle through buman skin. J Biomed Nanotech 2010;6:586-595.

Gupta R, Gupta M, Mangal S, Agrawal U, Vyas SP. Capsaicin-loaded vesicular systems designed for enhancing localized delivery for psoriasis therapy. Artif Cells Nanomed Biotechnol 2016;44(3):825-834. 
Honeywell-Nguyen PL, de Graaff AM, Groenink HW, Bouwstra JA. The in vivo and in vitro interactions of elastic and rigid vesicles with buman skin. Biochim Biophys Acta. 2002;1573(2):130-40.

Hsiao PF, Peng S, Tang TC, Lin SY, Tsai HC. Enhancing the in vivo transdermal delivery of gold nanoparticles using poly (ethylene glycol) and its oleylamine conjugate. Int J Nanomedicine 2016;11:1867-78.

Ioele G, Tavano L, De Luca M, Ragno G, Picci N, Muzzalupo R. Photostability and exvivo permeation studies on diclofenac in topical niosomal formulations. Int $\mathrm{J}$ Pharm 2015;494:490-497.

Khan R, Irchhaiya R. Niosomes: a potential tool for novel drug delivery. J Pharm Investig 2016;46:195-204.

Kumar GP, Rajeshwarrao P. Nonionic surfactant vesicular systems for effective drug delivery-an overview. Acta Pharm Sin B 2011;1(4):208-219.

Lather V, Sharma D, Pandita D. Proniosomal gel-mediated transdermal delivery of bromocriptine: in vitro and ex vivo evaluation. J Exp Nanosci 2016;11(13):10441057.

Lee J, Kim J, Go J, Lee JH, Han D-W, Hwang D et al. Transdermal treatment of the surgical and burned wound skin via phytochemical-capped gold nanoparticles. Colloids Surf B: Biointerfaces 2015;135:166-174.

Madan JR, Ghuge NP, Dua K. Formulation and evaluation of proniosomes containing lornoxicam. Drug Deliv Transl Res 2016;6:511-518.

Manca ML, Manconi M, Nacher A, Carbone C, Valenti D, Maccioni AM et al. Development of novel diolein-niosomes for cutaneous delivery of tretinoin: Influence of formulation and in vitro assessment. Int J Pharm 2014;477:176-186.

Mangalathillam S, Rejinold NS, Nair A, Lakshmanan V-K, Nair SV, Jayakumar R. Curcumin loaded chitin nanogels for skin cancer treatment via the transdermal route. Nanoscale 2012;4:239-250.

Mavuso S, Marimuthu T, Choonara YE, Kumar P, du Toit LC, Pillay V. A Review of Polymeric Colloidal Nanogels in Transdermal Drug Delivery. Cur Pharm Design 2015;21:2801-2813.

Mezei M, Gulasekharam V. Liposomes - a selective drug delivery system for the topical route of administration. Lotion dosage form. Life Sci 1980;26:1473-1477.

Mezei M, Gulasekharam V. Liposomes - a selective drug delivery system for the topical route of administration: gel dosage form. J Pharm Pharmacol 1982;34:473-474.

Moghddam SRM, Ahad A, Aqil M, Imam SS, Sultana Y. Formulation and optimization of niosomes for topical diacerein delivery using 3-factor, 3-level Box-Bebnken design for the management of psoriasis. Mater Sci Eng: C 2016; 69:789-797.

Monteiro-Riviere NA, Riviere JE. Interaction of nanomaterials with skin: Aspects of absorption and biodistribution. Nanotoxicology 2009;3:188-193.

Mordorsky B, Landriscina A, Friedman A. An overview of Nanomaterials in Dermatolog. In Nanoscience in Dermatology 2016, pp 31-46.

Morilla MJ, Romero EL. Carrier deformability in Drug Delivery. Cur Pharm Design, 2016;22:1118-1134.

Müller RH, Radtke M, Wissing SA. Solid lipid nanoparticles (SLN) and nanostructured 
lipid carriers (NLC) in cosmetic and dermatological preparations. Adv Drug Del Rev 2002;54:S131-S155.

Ogiso T, Niinaka N, Iwaki M. Mechanism for enhancement effect of lipid disperse system on percutaneous absorption. J Pharm Sci. 1996;85(1):57-64.

Otsuka H, Nagasaki Y, Kataoka K. PEGylated nanoparticles for biological and pharmaceutical applications. Adv Drug Del Rev 2003;55:403-419.

Owens DE III, Peppas NA. Opsonization, biodistribution, and pharmacokinetics of polymeric nanoparticles. Int J Pharm 2006;307:93-102.

Pando D, Matos M, Gutiérrez G, Pazos C. Formulation of resveratrol entrapped niosomes for topical use. Colloids Surf B: Biointerfaces 2015;128:398-404.

Papakostas D, Rancan F, Sterry W, Blume-Peytavi U, Vogt A. Nanoparticles in dermatology. Arch Dermatol Res 2011;303:533-550.

Pardeike J, Hommoss A, Müller RH. Lipid nanoparticles (SLN, NLC) in cosmetic and pharmaceutical dermal products. Int J Pharm 2009;366:170-184.

Paul A, Cevc G, Bachhawat BK. Transdermal immunization with large proteins by means of ultradeformable drug carriers. J Pharm Sci 1995;96(1):145-155.

Pierre MBR, Tedesco AC, Marchetti JM, Bentley MV. Stratum corneum lipids liposomes for the topical delivery of 5-aminolevulinic acid in photodynamic therapy of skin cancer: preparation and in vitro permeation study. BMC Dermatol 2001;1(5).

Rancan F, Asadian-Birjand M, Dogan S, Graf C, Cuellar L, Lommatzsch S et al. Effects of thermoresponsivity and softness on skin penetration and cellular uptake of polyglycerol-based nanogels. J Contr Rel 2016;228:159-169.

Rockall AG, Sohaib SA, Harisinghani MG, Babar SA, Singh N, Jeyarajah AR et al. Diagnostic Performance of Nanoparticle-Enhanced Magnetic Resonance Imaging in the Diagnosis of Lymph Node Metastases in Patients With Endometrial and Cervical Cancer. J Clin Oncol 2005;23:2813-2821.

Romero EL, Morilla MJ. Highly deformable and highly fluid vesicles as potential drug delivery systems: theoreticaland practical considerations. Int J Nanomedicine 2013;8:3171-3186.

Rouse JG, Yang J, Ryman-Rasmussen JP, Barron AR, Monteiro-Riviere NA. Effects of Mechanical Flexion on the Penetration of Fullerene Amino Acid-Derivatized Peptide Nanoparticles through Skin. Nano Lett 2007;7:155-160.

Ryman-Rasmussen JP, Riviere JE, Monteiro-Riviere NA. Penetration of Intact Skin by Quantum Dots with Diverse Physicochemical Properties. Toxicol Sci 2006;91: 159-165.

Samah NHA, Heard CM. Enhanced in vitro transdermal delivery of caffeine using a temperature- and $p H$-sensitive nanogel, poly(NIPAM-co-AAc). Int $\mathrm{J}$ Pharm 2013;453:630-640.

Santini B, Zanoni I, Marzi R, Cigni C, Bedoni M, Gramatica F, et al. Cream formulation impact on topical administration of engineered colloidal nanoparticles. PLoS One 2015;10:e0126366.

Schäfer-Korting M, Mehnert W, Korting H-C. Lipid nanoparticles for improved topical application of drugs for skin diseases. Adv Drug Del Rev 2007;59:427-443.

Schreief H, Bouwstrab J. Liposomes and niosomes as topical drug carriers: dermal and 
transdermal drug delivery. J Contr Rel 1994;30:1-15.

Šmejkalová D, Muthný T, Nešporová K, Hermannová M, Achbergerová E, HuertaAngeles $\mathrm{G}$ et al. Hyaluronan polymeric micelles for topical drug delivery. Carbohydr Polym 2017;156:86-96.

Sonavane G, Tomoda K, Sano A, Ohshima H, Terada H, Makino K. In vitro permeation of gold nanoparticles through rat skin and rat intestine: Effect of particle size. Colloids Surf B: Biointerfaces 2008;65:1-10.

Song CK, Balakrishnan P, Shim C, Chung S, Chong S, Kim D. A novel vesicular carrier, transethosome, for enhanced skin delivery of voriconazole: Characterization and in vitro/in vivo evaluation. Colloids Surf B: Biointerfaces 2012;92:299-304.

Song YK, Hyun SY, Kim HT, Kim CK, Oh JM. Transdermal delivery of low molecular weight heparin loaded in flexible liposomes with bioavailability enhancement: comparison with ethosomes. J Microencapsul 2011;28(3):151-8.

Song YK, Kim CK. Topical delivery of low-molecular-weight heparin with surfacecharged flexible liposomes. Biomaterials 2006;27(2):271-80.

Swain S, Beg S, Singh A, Patro ChN, Rao ME. Advanced techniques for penetration enhancement in transdermal drug delivery system. Curr Drug Deliv. 2011;8:456-473.

Tang L, Zhang CL, Song GM, Jin X, Xu Z. In vitro skin penetration and metabolic path of quantum dots. Sci China Life Sci 2013;56:181-188.

Touitou E, Dayana N, Bergelson L, Godina B, Eliaz M. Ethosomes - novel vesicular carriers for enhanced delivery: characterization and skin penetration properties. J Contr Rel 2000;65:403-418.

Trommer H, Neubert RHH. Overcoming the Stratum Corneum: The Modulation of Skin Penetration. Skin Pharmacol Physiol 2006;19:106-121.

Try C, Moulari B, Béduneau A, Fantini O, Pin D, Pellequer Y et al. Size dependent skin penetration of nanoparticles in murine and porcine dermatitis models. Eur J Pharm Biopharm 2016;100:101-108.

Vauthier C, Bouchemal K. Methods for the preparation and manufacture of polymeric nanoparticles. Pharm Res 2009;26:1025-58.

Vogt A, Combadiere B, Hadam S, Stieler KM, Lademann J, Schaefer H, et al. 40 nm, but not 750 or 1,500 nm, Nanoparticles Enter Epidermal CD1a+ Cells after Transcutaneous Application on Human Skin. J Inv Dermatol 2006;126:1316-1322.

Wiedersberg S, Guy RH. Transdermal drug delivery: 30+ years of war and still fighting! J Contr Rel 2014;190:150-156.

William AC, Barry BW. Penetration enhancers. Adv. Drug Del. Rev. 2004;56:603-618.

Wissing S, Lippacher A, Muller R. Investigations on the occlusive properties of solid lipid nanoparticles (SLN). J Cosmet Sci 2001;52:313-24.

Yasam VR, Jakki SL, Natarajan J, Venkatachalam S, Kuppusamy G, Sood S et al. A novel vesicular transdermal delivery of nifedipine - preparation, characterization and in vitro/in-vivo evaluation. Drug Deliv 2016;23(2):619-630.

Zhang LW, Monteiro-Riviere NA. Assessment of quantum dot penetration into intact, tape-stripped, abraded and flexed skin. Skin Pharmacol Physiol 2008;21:166188.

Zheng D, Giljohann DA, Chen DL, Massich MD, Wang X-Q, Iordanov H et al. Topical 
delivery of siRNA-based spherical nucleic acid nanoparticle conjugates for gene regulation. Proc Natl Acad Sci USA 2012;109:11975-11980.

Zidan AS, Hosny KM, Ahmed OAA, Fahmy UA. Assessment of simvastatin niosomes for pediatric transdermal drug delivery. Drug Delivery 2016;23(5):1536-1549. 